\title{
Relationship between oxygen consumption kinetics and BODE Index in COPD patients
}

\author{
Audrey Borghi-Silva' \\ Thomas Beltrame ${ }^{1,2}$ \\ Michel Silva Reis' \\ Luciana Maria Malosá \\ Sampaio 3 \\ Aparecida Maria Catai' \\ Ross Arena ${ }^{4}$ \\ Dirceu Costa ${ }^{3}$ \\ 'Cardiopulmonary Physiotherapy \\ Laboratory, Nucleus of Research in \\ Physical Exercise, Federal University \\ of São Carlos, São Carlos, SP, Brazil; \\ ${ }^{2}$ Faculty of Applied Health Sciences, \\ University of Waterloo, Waterloo, \\ ON, Canada; ${ }^{3}$ Rehabilitation Sciences \\ Master's Program, Universidade \\ Nove de Julho, Sao Paulo, SP, Brazil; \\ ${ }^{4}$ Division of Physical Therapy, \\ Department of Orthopedics, Division \\ of Cardiology, Department of Internal \\ Medicine, and Latin American and \\ Iberian Institute, University of New \\ Mexico, Albuquerque, NM, USA
}

This article was published in the following Dove Press journal: International Journal of COPD

16 October 2012

Number of times this article has been viewed

Background and objective: Patients with chronic obstructive pulmonary disease (COPD) present with reduced exercise capacity due to impaired oxygen consumption $\left(\mathrm{VO}_{2}\right)$, caused primarily by pulmonary dysfunction and deleterious peripheral adaptations. Assuming that COPD patients present with slower $\mathrm{VO}_{2}$ and heart rate (HR) on-kinetics, we hypothesized that this finding is related to disease severity as measured by the BODE Index. In this context, the present study intends to evaluate the relationship between $\mathrm{VO}_{2}$ uptake on-kinetics during highintensity exercise and the BODE Index in patients with COPD.

Methods: Twenty males with moderate-to-severe stable COPD and 13 healthy control subjects matched by age and sex were evaluated. COPD patients were screened by the BODE Index and then underwent an incremental cardiopulmonary exercise test and a constant speed treadmill session at $70 \%$ of maximal intensity for 6 minutes. The onset of the exercise (first 360 seconds) response for $\mathrm{O}_{2}$ uptake and $\mathrm{HR}$ was modeled according to a monoexponential fit.

Results: Oxygen consumption and HR on-kinetics were slower in the COPD group compared with controls. Additionally, $\mathrm{VO}_{2}$ on-kinetic parameters revealed a strong positive correlation ( $\mathrm{r}=0.77, P<0.05)$ with BODE scores and a moderate negative correlation with walking distance $(\mathrm{r}=-0.45, P<0.05)$.

Conclusion: Our data show that moderate-to-severe COPD is related to impaired oxygen delivery and utilization during the onset of intense exercise.

Keywords: COPD, $\mathrm{VO}_{2}$ on-kinetics, heart rate, BODE Index

\section{Introduction}

Patients with chronic obstructive pulmonary disease (COPD) present with reduced exercise capacity due to a combination of factors including impaired cardiopulmonary responses, ${ }^{1}$ leading to inadequate pulmonary oxygen $\left(\mathrm{O}_{2}\right)$ uptake and delivery to active skeletal muscle, ${ }^{2,3}$ derangements in the intracellular biochemical reactions in relation to mitochondrial oxygen consumption $\left(\mathrm{VO}_{2}\right)^{4,5}$ and/or mechanical abnormalities.

Following the onset of constant workload exercise, the $\mathrm{O}_{2}$ uptake increase (ie, onkinetics) in COPD patient, which can be characterized by the time required for $\mathrm{VO}_{2}$ to achieve steady state in response to physical stress, is slowed when compared to apparently healthy matched controls. From a clinical context, $\mathrm{O}_{2}$ uptake on-kinetics has been shown to have even better prognostic value than peak $\mathrm{VO}_{2}$ in chronic disease populations. ${ }^{6,7}$ Moreover, recent studies have shown that, like $\mathrm{O}_{2}$ uptake on-kinetics, heart rate (HR) onkinetics, are also slower in COPD patients. ${ }^{1,8}$ Some investigators ${ }^{1,8,9}$ have postulated that slower $\mathrm{O}_{2}$ uptake and $\mathrm{HR}$ on-kinetics ${ }^{10}$ may reflect the adjustment of both oxygen delivery

Correspondence: Audrey Borghi-Silva Cardiopulmonary Physiotherapy Laboratory, Nucleus of Research in Physical Exercise, Federal University of São Carlos, São Carlos, SP, Brazil; Rodovia Washington Luís km 235, Bairro Monjolinho, CEP I3565-905 São Carlos, SP, Brasil

Tel +55 I6 335I 8952

Email audrey@ufscar.br 
and muscle metabolism during physical exercise ${ }^{11}$ as well as exercise performance/functional capacity in these patients.

Additionally, forced expiratory volume in 1 second $\left(\mathrm{FEV}_{1}\right)$, a measurement that quantifies the degree of airway obstruction, is often used to diagnose and quantify COPD severity. ${ }^{12}$ Moreover, the rate of decline in $\mathrm{FEV}_{1}$ is a good marker of disease progression and mortality, however, it does not adequately reflect systemic manifestations that contribute to reduced exercise performance in COPD. ${ }^{13}$

The BODE Index, comprising of body mass index, airflow obstruction, dyspnea, and exercise capacity, has shown to be superior to $\mathrm{FEV}_{1}$ in predicting clinical outcomes in the COPD population. ${ }^{13}$ This multivariate scoring system can provide useful prognostic information in COPD and reflects functional disability induced by systemic consequences of this disease. ${ }^{13,14}$ Recently, it have been suggested that serum C-reactive protein, an important systemic inflammation marker, combined with the BODE Index, has a higher combined prognostic value for patients with COPD. ${ }^{15}$ In this context, on-kinetic alterations have been shown to be useful parameters to objectively evaluate the systemic consequences related to inability to perform submaximal exercise in COPD patients. ${ }^{1}$

In this context, the present study intends to evaluate the relationship between the metabolic demand during the onset of exercise and the BODE Index in patients with COPD. Assuming that COPD patients present with slower $\mathrm{O}_{2}$ uptake and HR on-kinetics, which is an important index of exercise performance, we hypothesize that the slower $\mathrm{O}_{2}$ uptake onkinetic response is related to the level of disease severity, as represented by the BODE Index.

\section{Methods}

\section{Study population}

The study population was comprised of 20 men that volunteered to participate in the study with clinical and functional diagnosis of COPD according to the Global Initiative for Obstructive Lung Disease ${ }^{16}$ criteria, presenting with a FEV ${ }_{1}$ / forced vital capacity (FVC) of $<0.7$ and a postbronchodilator $\mathrm{FEV}_{1}<60 \%$ predicted.

No subject in the COPD group had ever participated in a pulmonary rehabilitation program. Criteria for inclusion were: adherence to the individually prescribed treatment regimen and disease stability indicated by no change in medication dosage or exacerbation of symptoms for at least 1 month prior to study enrollment. All patients presented with dyspnea during daily activities (Medical Research Council [MRC] grades II-III). ${ }^{17}$ Exclusion criteria were: malignancy, orthopedic or neurological conditions affecting the ability to exercise, peripheral arterial disease, clinically apparent heart failure, and/or any renal, hepatic, or inflammatory disease.

Thirteen healthy control subjects (control group [CG]), matched according to age and sex, were also included in this investigation. Our laboratory posted an announcement at the university inviting healthy subjects to enroll as control subjects for this study. Subjects in the CG were free of any history of arterial hypertension, serious cardiac disease, or associated lung disease, were nonsmokers, and had not participated in regular daily physical activity during the past year. All participants signed a written informed consent and the study design was approved by the Human Ethics Committee of the Universidade Federal de Sao Carlos, Brazil, in compliance with the Declaration of Helsinki.

\section{Measurements}

\section{Lung function}

All patients underwent spirometry to quantify $\mathrm{FEV}_{1}$ and $\mathrm{FVC}$ according to American Thoracic Society recommendations. ${ }^{16}$ The values obtained were compared to the predicted normal values of Knudson et al. ${ }^{18}$ Spirometry was performed using a Vitalograph ${ }^{\circledR}$ Hand-Held 2120 instrument (Ennis, Ireland), which was calibrated before each test according to manufacturer recommendations using a 1-L syringe.

\section{Six-minute walking test (6MWT)}

Performed as described by American Thoracic Society Guidelines. ${ }^{19}$ Two tests were performed on alternating days within 48 hours. The test with the greatest six-minute walking distance (6MWD) was considered for analysis, as the first test tends to underestimate exercise capacity due to the subject's lack of familiarity with the test. ${ }^{19}$ Each patient was instructed to walk from one end to the other, covering as much ground as possible during the allotted time and all patients were given standardized encouragement during the test.

\section{BODE Index}

Measurements to calculate this index were performed in all subjects in the COPD group. The BODE Index (B: body mass index; O: degree of airflow obstruction; D: dyspnea; E: exercise capacity), is a multidimensional index comprising of $\mathrm{BMI}$, degree of airway obstruction $\left(\mathrm{FEV}_{1}\right)$, functional dyspnea (MRC dyspnea scale), and exercise capacity via the 6MWT. For calculation of the BODE Index, we used an empirical model as previously described. ${ }^{13}$ For the first parameter, the value was 0 or 1 . For the last three parameters, $\mathrm{FEV}_{1}$, distance walked in 6 minutes, and score on the modified MRC dyspnea 
scale, the patients received points ranging from 0 (lowest value) to 3 (maximal value). The points for each variable were added, so that the BODE Index was the sum of points for each variable, ranging from 0 to 10 in each subject. The BODE Index can be divided into four quartiles: quartile I is a score of $0-2$; quartile II is a score of 3-4; quartile III a score of 5-6; and quartile IV a score of 7-10.

\section{Cardiopulmonary exercise testing (CPX)}

Incremental symptom-limited exercise testing was performed on a treadmill using a computer-based ventilatory expired gas analysis system $\left(\mathrm{VO}_{2000}\right.$; Medgraphics Corp, St Paul, MN) in accordance with a previously described protocol. ${ }^{20}$ The $\mathrm{VO}_{2000}$ uses a galvanic fuel cell for the oxygen analyzer (range 0\%-96\%) and a nondispersive infrared carbon dioxide analyzer (range $0 \%-10 \%$ ), both of which were calibrated prior to each exercise test as per manufacturer instructions. A low-flow pneumotach (preVent Pneumotach, MGC; range $2-30 \mathrm{~L} \cdot \mathrm{min}^{-1}$ ) was calibrated with a $3-\mathrm{L}$ volume syringe. Acceptable interday reliability for ventilation (CV $7.3 \%-8.8 \%)$, oxygen consumption $\left(\mathrm{VO}_{2}\right)$ and carbon dioxide $\left(\mathrm{VCO}_{2} ; \mathrm{CV} 5.3 \%-6.0 \%\right)$ has been demonstrated in a previous study. ${ }^{21} \mathrm{VO}_{2}$ (in $\mathrm{mL} \cdot \mathrm{min}^{-1}$ ) was sampled for each three breaths and 10 -second averaged data were recorded for further analysis. Oxyhemoglobin saturation $\left(\mathrm{SpO}_{2}, \%\right)$ was determined by pulse oximetry (8500A; Nonin, Plymouth, MN). Subjects were also asked to rate their "shortness of breath" at exercise cessation using the $0-10$ Borg's category-ratio scale. ${ }^{22}$

\section{Constant speed exercise test (CSET)}

The CSET were performed at $70 \%$ of the previously determined speed (during CPX) at $3^{\circ}$ inclination on a treadmill, for 6 minutes. During the CSET, $\mathrm{VO}_{2}, \mathrm{SpO}_{2}, \mathrm{HR}$, and the electrocardiogram were continuously monitored. $\mathrm{The} \mathrm{VO}_{2}$ and HR data from the onset of CSET were used for onkinetics analysis.

\section{On-kinetics analysis}

In order to understand the behavior of $\mathrm{HR}$ and $\mathrm{VO}_{2}$ during the onset of exercise, an on-kinetics analysis was performed for each variable. ${ }^{23}$ The $\mathrm{CSET} \mathrm{VO}_{2}$ and $\mathrm{HR}$ data obtained were entered and analyzed into SigmaPlot 10.0, Systat Software (San Jose, CA) to be analyzed. In order to eliminate an occasional errant data point arising from coughs, sighs or swallows, $\mathrm{VO}_{2}$ data that surpassed four standard deviations from the local mean was omitted. ${ }^{24,25}$ The onset of exercise (first 360 seconds) response was modeled using a monoexponential fit.

$$
f(t)=a_{0}+a\left(1-e^{-(t-T D) / \tau}\right)
$$

where ' $\mathrm{f}(\mathrm{t})$ ' represents $\mathrm{VO}_{2}$ or HR at any time $(\mathrm{t})$; ' $\mathrm{a}_{0}$ ' is the baseline value corresponding to a mean value at the last minute of baseline prior to the constant workload test; ' $a$ ' is the amplitude, ie, steady-state increase above baseline; ' $\tau$ ' is the time constant, ie, the time taken to reach $63 \%$ of the function; and 'TD' is the time delay of the function. A warm-up was performed to minimize the effects of the cardiodynamic phase on the $\mathrm{O}_{2}$ uptake on-kinetics response. ${ }^{26}$ Additionally, the mean response time (MRT, the time taken to reach $63 \%$ of total response following the onset of exercise) was calculated as the weighted sum of the 'TD' and ' $\tau$ '. ${ }^{27}$ The inclusion of 'TD' in this equation was established due the possibility that $\mathrm{VO}_{2}$ or HR does not start to rise immediately at the onset of the imposed workload. ${ }^{28}$ Given the fact that ' $\tau$ ' and MRT are time parameters from an exponential function, the lower its values, the faster the $\mathrm{VO}_{2}$ and/or HR response. ${ }^{29,30}$

To determine the parameters of the best curve fit, a nonlinear algorithm of least squares was used. This model adopts the minimization of the sum of square errors as a criterion for convergence. The ' $a$ ' and ' $a_{0}$ ' describe the parameters related to the component of $\mathrm{Y}$ axis $\left(\mathrm{VO}_{2}\right.$ or $\left.\mathrm{HR}\right)$, the ' $\tau$ ' and 'TD' describe the parameters related to $\mathrm{X}$ axis (time). Only the function with $r>95 \%$ was included in final analysis, which guarantees a good quality of fit. ${ }^{28}$

\section{Statistical analysis}

Sample size was based on the analysis of the ' $\tau \mathrm{VO}_{2}$ ' values obtained in a pilot study ( 5 subjects) with $\beta=0.8$ and $\alpha=0.05$ (MedCalc Software, version 11.2.1.0 (Mariakerke, Belgium)). The results suggested at least 10 subjects in each group with differences of 5 seconds were needed to be sufficiently powered. The Shapiro-Wilk test was used to verify data distribution and heterogeneous variance (Levene test). Unpaired $t$-tests were used in the current analysis given all parameters demonstrated a normal distribution. The data were presented as mean and standard deviation. We used Pearson correlation analysis to evaluate the relationship between the variables. The level of significance was set at 5\% (SigmaPlot version 11.0).

\section{Results Anthropometric characteristics}

Table 1 lists the demographic characteristics of the subjects studied. There were no differences in age or anthropometric characteristics. Two patients had GOLD stage II COPD, ten had GOLD stage III and eight had stage IV of COPD. As expected, COPD subjects had lower values of pulmonary 
Table I Age, anthropometric, and functional characteristics of COPD and control (CG) groups

\begin{tabular}{|c|c|c|c|}
\hline & $\operatorname{COPD}(n=20)$ & CG $(n=13)$ & $P$ value \\
\hline Age (years) & $67.1( \pm 8.7)$ & $64.8( \pm 8.9)$ & 0.44 \\
\hline \multicolumn{4}{|c|}{ Anthropometric characteristics } \\
\hline Body mass (kg) & $62.6( \pm 12.9)$ & $64.8( \pm 76)$ & 0.31 \\
\hline Height $(\mathrm{cm})$ & $1.61( \pm 0.08)$ & $1.63( \pm 0.08)$ & 0.42 \\
\hline BMI $\left(\mathrm{kg} / \mathrm{m}^{2}\right)$ & $24.2( \pm 4.6)$ & $25.3( \pm 3.46)$ & 0.24 \\
\hline \multicolumn{4}{|c|}{ Pulmonary function } \\
\hline $\mathrm{VO}_{2 \text { peak }}(\mathrm{mL} \cdot \mathrm{min} / \mathrm{kg})$ & $15.05( \pm 3.32)$ & $21.92( \pm 8.17)$ & 0.002 \\
\hline $\mathrm{FEV}_{1}(\mathrm{~L})$ & $0.8( \pm 0.24)$ & $2.54( \pm 0.6)^{*}$ & $<0.001$ \\
\hline $\mathrm{FEV}, \%$ & $31.8( \pm 9.5)$ & $104( \pm 16.8)^{*}$ & $<0.001$ \\
\hline FVC \% & $66.7( \pm 17.2)$ & $108.8( \pm 18.3)^{*}$ & $<0.001$ \\
\hline $\mathrm{FEV}_{1} / \mathrm{FVC}$ & $0.42( \pm 0.08)$ & $0.77( \pm 0.06)^{*}$ & $<0.001$ \\
\hline \multicolumn{4}{|l|}{ 6MWT } \\
\hline Distance $(m)$ & $358.6( \pm I I I)$ & $552( \pm 91.3)^{*}$ & $<0.001$ \\
\hline Distance (\% predict) & $70.4( \pm 22.3)$ & $106.2( \pm 18.1)^{*}$ & $<0.001$ \\
\hline $\mathrm{VO}_{2}\left(\% \mathrm{VO}_{2 \text { peak }}\right)$ & $72.46( \pm 32.93)$ & $70.52( \pm 27.58)$ & 0.55 \\
\hline \multicolumn{4}{|l|}{ Function capacity } \\
\hline MRC-0 & 4 & - & \\
\hline MRC-I & 4 & - & \\
\hline MRC-2 & 3 & - & \\
\hline MRC-3 & 1 & - & \\
\hline MRC-4 & 8 & - & \\
\hline Mean BODE score & $5.6( \pm 1.9)$ & - & \\
\hline Quartile I/2/3/4 & $1 / 4 / 10 / 5$ & - & \\
\hline
\end{tabular}

Notes: Data expressed as mean ( \pm standard deviation); ${ }^{*} P<0.05$ Unpaired $t$-test. Abbreviations: BMI, body mass index; COPD, chronic obstructive pulmonary disease; $\mathrm{FEV}_{1}$, forced expiratory volume in I second; FVC, forced vital capacity; MRC, Medical Research Council; 6MWT, Six-Minute Walking Test.

function compared with healthy controls. All subjects completed the 6MWT protocol without complication.

Table 2 lists values of $\mathrm{O}_{2}$ uptake on-kinetics analysis achieved during the CSET. The COPD group exercise at a lower power output and achieved a lower $\mathrm{VO}_{2}$ and $\mathrm{HR}$ "steady state" ('a', amplitude). Moreover, the time constant ' $\tau$ ' associated with reaching $\mathrm{VO}_{2}$ steady state was longer in COPD. The $\mathrm{VO}_{2}$ and HR MRT was longer in the COPD group in compared with the $\mathrm{CG}(P<0.05)$.

The Pearson correlation presented with a modest relationship between 6MWT distance and $\tau \mathrm{VO}_{2}$ (Figure 1B; $\mathrm{r}=-0.45, P<0.05)$ as well as $\mathrm{FEV}_{1}(\mathrm{r}=-0.49, P=0.05)$. Interestingly, however, the relationship between the BODE Index and $\tau \mathrm{VO}_{2}$ demonstrated a strong correlation (Figure $1 \mathrm{~A} ; \mathrm{r}=0.77, P<0.01$ ).

Finally, Figure 2 illustrates the mean fit of $\mathrm{O}_{2}$ uptake and HR on-kinetics during CSET performed on a treadmill, which shows significant differences between the COPD and CG $(P<0.05)$. For the construction of these functions, the values obtained for the $\mathrm{O}_{2}$ uptake on-kinetics analysis (the same listed in Table 2) were inserted in the kinetics equation described above and plotted as a function.

\section{Discussion}

The main important finding of the present study is that $\tau \mathrm{VO}_{2}$ demonstrated a strong correlation with the BODE Index. In addition, this study revealed that $\mathrm{O}_{2}$ uptake and HR onkinetics were slower in the COPD group compared to the CG during CSET. These results indicate that a combined analysis of exercise on-kinetic responses and the BODE Index may serve as an important marker of diminished functional capacity, potentially indicating a worse prognosis in this patient population.

\section{On-kinetics of oxygen uptake and heart rate}

Due the fact that parameters " $\tau$ " and "MRT" are exponential time constants, ${ }^{29}$ lower values indicate a better adjustment to exercise and more favorable physiologic function.

Based on the kinetic responses observed in the current study, we found that $\mathrm{O}_{2}$ uptake and HR on-kinetics were slower (higher values of ' $\tau$ ' and 'MRT') in COPD patients compared to the CG during CSET on a treadmill. In accordance with our results, several investigators ${ }^{1,31,32}$ have reported that $\mathrm{O}_{2}$ uptake on-kinetics are delayed in patients with COPD during constant work rate exercise on a cycle ergometer. The exact mechanism of slowed on-kinetics in patients with COPD is unclear, but Chiappa et $\mathrm{al}^{1}$ demonstrated that it may be related to a prolonged $\mathrm{O}_{2}$ delivery and

Table 2 On-kinetics parameters obtained during constant workload exercise tests (CWET) in COPD and control groups

\begin{tabular}{|c|c|c|c|c|c|c|}
\hline & \multicolumn{3}{|l|}{$\mathrm{VO}_{2}$ kinetics } & \multicolumn{3}{|l|}{ HR kinetics } \\
\hline & COPD $(n=20)$ & Control $(n=13)$ & $P$ value & $\operatorname{COPD}(n=14)$ & Control $(n=I I)$ & $P$ value \\
\hline Baseline & $0.256 \pm 0.1$ & $0.3 \pm 0.3$ & 0.378 & $84.9 \pm 7.1$ & $80.6 \pm 9.4$ & 0.205 \\
\hline Amplitude & $0.37 \pm 0.2$ & $0.7 \pm 0.3^{*}$ & 0.001 & $29.3 \pm 17.1$ & $46.0 \pm 13.0 *$ & 0.015 \\
\hline MRT (s) & $73.9 \pm 23.1$ & $50.9 \pm 10.4^{*}$ & 0.002 & $129.3 \pm 52.1$ & $1 \mathrm{II} .7 \pm 40.7$ & 0.367 \\
\hline$\tau(\mathrm{s})$ & $61.8 \pm 25.5$ & $40.5 \pm 12.6^{*}$ & 0.009 & $126.2 \pm 51.8$ & $85.9 \pm 35.9 *$ & 0.039 \\
\hline
\end{tabular}

Notes: Data expressed as mean ( \pm standard deviation). Amplitude and baseline are $\mathrm{L} / \mathrm{min}$ and bpm for $\mathrm{VO}_{2}$ and $\mathrm{HR}$, respectively. Unpaired $t$-test: *statistically significant difference $(P<0.05)$ between COPD and control.

Abbreviations: HR, heart rate; COPD, chronic obstructive pulmonary disease; MRT, mean response time; $P$, statistical significance; $\tau$, time constant. 

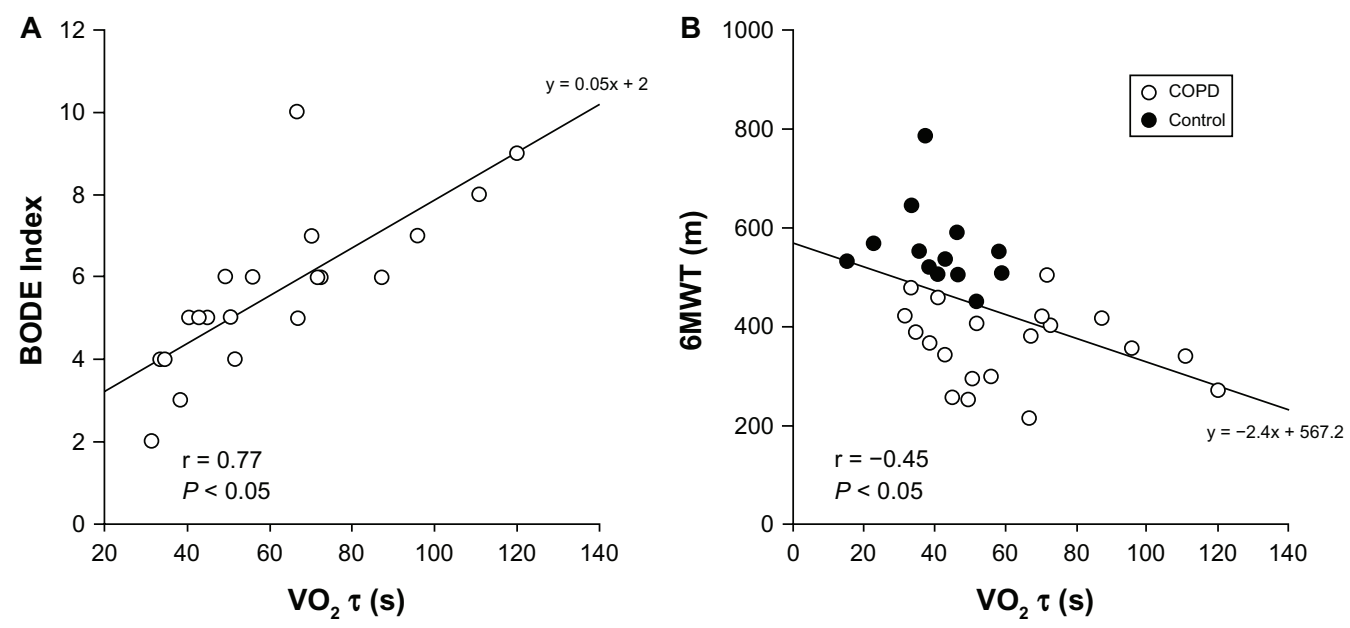

Figure I Relationship between the BODE Index $(\mathbf{A})$ and the 6MWT $(\mathbf{B})$ with the time constant $(\tau)$ for the on-transient of pulmonary oxygen $\left(\mathrm{O}_{2}\right)$ uptake in COPD patients. Abbreviations: COPD, chronic obstructive pulmonary disease; 6MWT, 6-Minute Walking Test; $\mathrm{VO}_{2} \tau$, oxygen uptake on kinetic.

utilization at the onset of exercise. ${ }^{6}$ It is widely recognized that disturbances in the diffusive and/or convective transport of $\mathrm{O}_{2}$ to skeletal muscle mitochondria ${ }^{33,34}$ and/or intramyocyte metabolic machinery ${ }^{35-37}$ could explain the attenuation of $\mathrm{O}_{2}$ uptake on-kinetics in patients with cardiopulmonary and metabolic disorders.

In fact, hypoxemia, ${ }^{3}$ autonomic imbalance, ${ }^{38}$ blood flow redistribution from peripheral to respiratory muscles, ${ }^{39,40}$ derangements in muscle vasodilatation capacity,${ }^{41}$ and increased intrathoracic and/or pleural pressures (swings on central hemodynamic adjustments) can all negatively impact the $\mathrm{O}_{2}$ uptake response at the onset of exercise. Some therapeutic strategies ${ }^{31,32,40,42}$ have been demonstrated to increase the $\mathrm{O}_{2}$ uptake on-kinetics speed, supporting the importance of different interventions on the respiratory-mechanical system in order to improve functional capacity in COPD patients.

The other important issue investigated in the current study is slower HR on-kinetics identified in the experimental
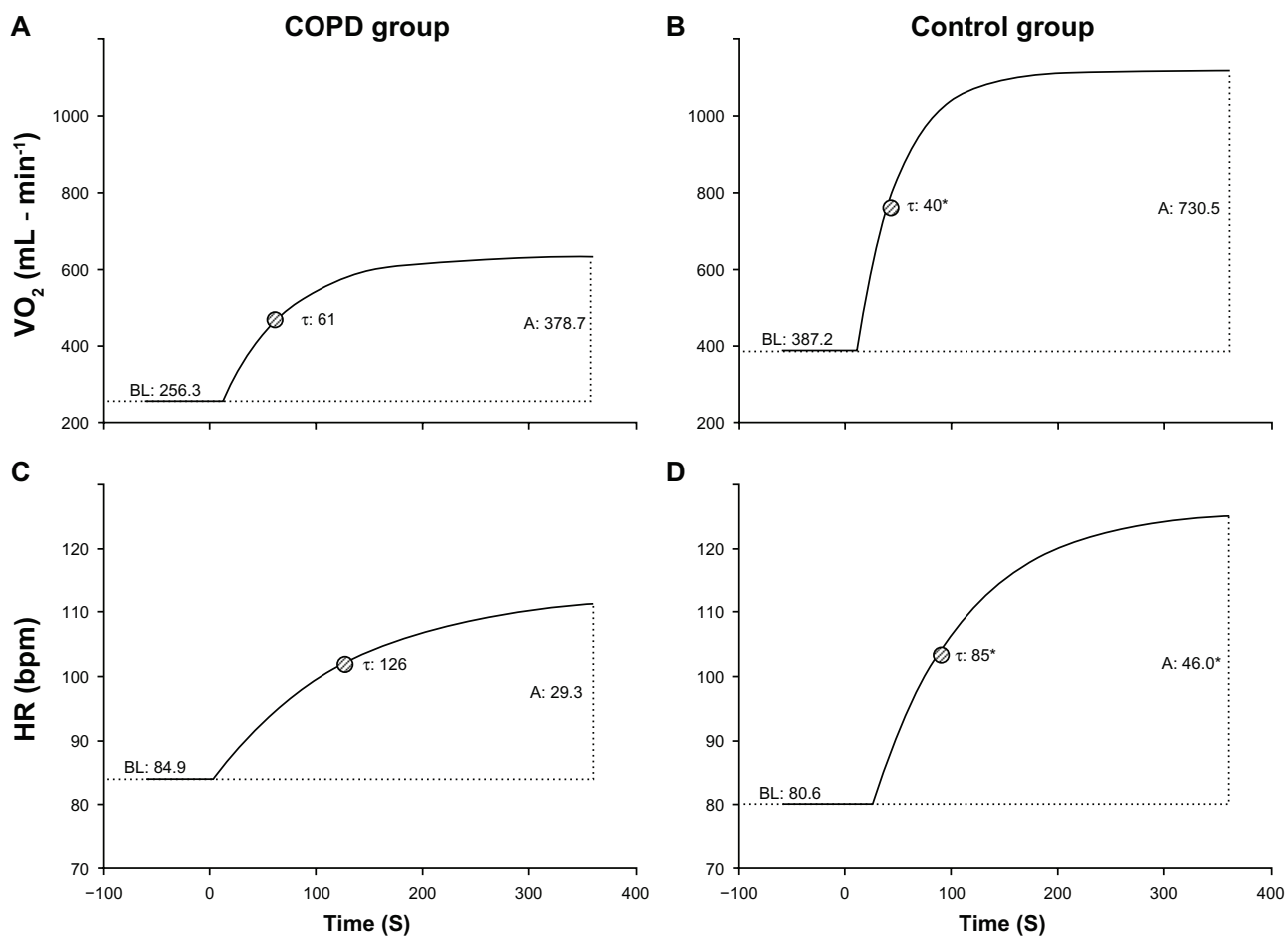

Figure 2 Illustration of the fitted curves using the means of $\mathrm{VO}_{2}(\mathbf{A}$ and $\mathbf{B})$ and $\mathrm{HR}(\mathbf{C}$ and $\mathbf{D})$ kinetics during the constant-speed exercise tests (CSET) performed on a treadmill at intense exercise (70\% of peak) in COPD (A and $\mathbf{C}$ ) and control patients (B and $\mathbf{D})$.

Abbreviations: COPD, chronic obstructive pulmonary disease; $\mathrm{HR}$, heart rate; $\mathrm{VO}_{2}$, oxygen consumption. 
group, which has been previously described in patients with COPD. ${ }^{1}$ In fact, cardiovascular responses that should help maintain adequate $\mathrm{O}_{2}$ delivery to contracting muscle are impaired in COPD. Supposedly, slower HR on-kinetics can be explained by autonomic imbalance, ${ }^{43}$ pulmonary vascular alteration, and/or effects of mechanisms of breathing on venous return. ${ }^{38}$ Therefore, the assessment of HR on-kinetics may have particular clinical utility in reflecting physiologic function, disease severity and the response to therapeutic interventions in this chronic disease population.

\section{On-kinetics: BODE Index relationship}

The BODE Index has proven useful in evaluating the severity of COPD. As this index incorporates measures of airway obstruction, body mass composition, symptomatology and functional capacity, it captures a comprehensive panel of limitations induced by COPD. Assuming that severe COPD induces expressive peripheral muscle dysfunction and functional limitation, it seems rational to suspect that these patients presented with slowed $\mathrm{O}_{2}$ uptake on-kinetics as an additional reflection of their advanced disease severity. Interestingly, however, in this regard the BODE Index demonstrated a strong correlation with $\mathrm{O}_{2}$ uptake on-kinetics. In fact, the correlation was much stronger than for the 6MWD or $\mathrm{FEV}_{1}$. These results may be explained by the fact that COPD has a systemic component that includes significant extrapulmonary effects that may contribute to disease severity variability amongst patients. In parallel, $\mathrm{O}_{2}$ uptake and $\mathrm{HR}$ on-kinetics may infer the impairment of central cardiorespiratory and/or peripheral muscle in these patients.

To the best of our knowledge, this study is the first to assess the relationship between the BODE Index and $\mathrm{O}_{2}$ uptake on-kinetics, which adds another dimension to BODE Index interpretation. Previous studies have shown that the BODE Index is correlated to other markers of functional performance. Regueiro et $\mathrm{al}^{44}$ evaluated 10 moderate to severe COPD patients and demonstrated a strong correlation between the sit-to-stand test, hand grip strength test and the 6MWT ( -0.86 against -0.45 in our study) and the BODE Index. These authors suggested that the BODE Index could be used to predict functional capacity. Simon et $\mathrm{al}^{45}$ demonstrated that 39 patients with moderate to severe COPD presented a significant relationship between the BODE Index and physical activity assessed by the London Chest Activity of Daily Living Scale score. These authors suggested that BODE Index can therefore assist in the interpretability of the London questionnaire. Another recent study ${ }^{46}$ was able to demonstrate that higher amounts of daily physical activity in
107 patients with moderate-to-severe COPD was associated with a lower BODE Index. In agreement, Mantoani et $\mathrm{al}^{47}$ found a significant moderate correlation between the BODE Index and amount of daily physical activity in 67 patients with COPD. Accordingly, the results of the current study add to this body of literature by demonstrating a correlation between the BODE Index and another marker of exertional physiology, $\mathrm{O}_{2}$ uptake on-kinetics. Thus, this allows us to infer that the BODE Index may reflect the degree of central/ peripheral physiologic dysfunction induced by COPD and manifested by slower $\mathrm{O}_{2}$ uptake and HR on-kinetics.

\section{Limitations of this study}

Firstly, it should be recognized that breath-by-breath analysis is the best way to obtain samples to fit the $\mathrm{O}_{2}$ uptake on-kinetic response, however, other authors ${ }^{48,49}$ have used this approach previously and showed reliability of the data collected ${ }^{50}$ with good fit results. Secondly, the protocol used in this study was conducted on a treadmill. In fact, protocols on a cycle ergometer allow for a more precise measurement of external work rate. However, in this study we aimed to assess the functional capacity of COPD patients using an exercise mode that may more closely mimic activities of daily living (ie, ambulation). Moreover, exercise tests on a treadmill have been used to assess the on-kinetic response in the past. ${ }^{25,51,52}$ Thirdly, we analyzed the time (' $\tau$ ') to achieve $63 \%$ of steady rate, which may be overestimated by $\tau$ HR if compared to other studies that used $\mathrm{T}_{1 / 2}\left(50 \%\right.$ of steady state). ${ }^{1}$ However, we observed that the current study found COPD subjects presented with slower HR on-kinetics when compared to the CG, indicating a central limitation in these patients. Finally, we used a 6-minute protocol to analyze HR on-kinetics in order to compare it with $\mathrm{O}_{2}$ uptake on-kinetic response. However, our results showed that the exponential model used to analyze the HR response may not be best represented by a 6-minute sample.

\section{Importance of this study}

Previous investigators have reported that COPD patients present with delayed $\mathrm{O}_{2}$ uptake on-kinetics, which was also demonstrated in the current study using a constant speed on a treadmill. However, no previous investigation demonstrated that the degree of COPD severity is related to the $\mathrm{O}_{2}$ uptake on-kinetic response. This is an important consideration as it adds another dimension to interpretation of the BODE Index, which is frequently employed in clinical practice. Delayed $\mathrm{O}_{2}$ uptake and HR on-kinetics may be related to the reduction in exercise tolerance associated with poor prognosis assessed by the BODE Index in COPD patients. 
Some therapeutic strategies that optimize exercise tolerance (ie, dynamic and/or strength training), accelerating exercise on-kinetics, may decrease the risk of exacerbations and death in these patients. ${ }^{53}$ Additionally, $\mathrm{O}_{2}$ uptake on-kinetics analysis can be used as a follow-up measure in many different therapeutic interventions.

\section{Conclusion}

In general, our data show that patients with moderate to severe COPD have impaired $\mathrm{O}_{2}$ uptake and HR on-kinetics at the onset of intense exercise on a treadmill. In addition, we found a strong relationship between the BODE Index and $\mathrm{O}_{2}$ uptake on-kinetics. Thus, $\mathrm{COPD}$ severity leads to an attenuated on-kinetics response during exercise which can be captured by the BODE Index.

\section{Acknowledgments}

This study received financial support from FAPESP (2009/01842-0) and CNPq (\#483945/2007-2). The coauthors Thomas Beltrame (\#130549/2011-8) and Michel Silva Reis received CNPq and PNPD-Capes fellowship, respectively. A Borghi-Silva is an Established Investigator (level II) of the Conselho Nacional de Desenvolvimento Científico e Tecnológico (CNPq), Brazil.

\section{Disclosure}

The authors report no conflicts of interest in this work.

\section{References}

1. Chiappa GR, Borghi-Silva A, Ferreira LF, et al. Kinetics of muscle deoxygenation are accelerated at the onset of heavy-intensity exercise in patients with COPD: relationship to central cardiovascular dynamics. J Appl Physiol. 2008;104(5):1341-1350.

2. Sala E, Roca J, Marrades RM, et al. Effects of endurance training on skeletal muscle bioenergetics in chronic obstructive pulmonary disease. Am J Respir Crit Care Med. 1999;159(6):1726-1734.

3. Somfay A, Porszasz J, Lee SM, Casaburi R. Effect of hyperoxia on gas exchange and lactate kinetics following exercise onset in nonhypoxemic COPD patients. Chest. 2002;121(2):393-400.

4. Wuyam B, Payen JF, Levy P, et al. Metabolism and aerobic capacity of skeletal muscle in chronic respiratory failure related to chronic obstructive pulmonary disease. Eur Respir J. 1992;5(2):157-162.

5. Casaburi R. Skeletal muscle dysfunction in chronic obstructive pulmonary disease. Med Sci Sports Exerc. 2001;33(Supp1 7): S662-S670.

6. Shimizu N, Koike A, Koyama Y, Kobayashi K, Marumo F, Hiroe M. Kinetics of pulmonary gas exchange during and while recovering from exercise in patients after anterior myocardial infarction. Jpn Circ J. 1999;63(6):459-466.

7. Poole DC, Hirai DM, Copp SW, Musch TI. Muscle oxygen transport and utilization in heart failure: implications for exercise (in)tolerance. Am J Physiol Heart Circ Physiol. 2012;302(5):H1050-H1063.

8. Laveneziana P, Valli G, Onorati P, Paoletti P, Ferrazza AM, Palange P. Effect of heliox on heart rate kinetics and dynamic hyperinflation during high-intensity exercise in COPD. Eur J Appl Physiol. 2011;111(2): 225-234.
9. Puente-Maestu L, Sanz ML, Sanz P, Nunez A, Gonzalez F, Whipp BJ. Reproducibility of the parameters of the on-transient cardiopulmonary responses during moderate exercise in patients with chronic obstructive pulmonary disease. Eur J Appl Physiol. 2001;85(5): 434-441.

10. Nery LE, Wasserman K, Andrews JD, Huntsman DJ, Hansen JE, Whipp BJ. Ventilatory and gas exchange kinetics during exercise in chronic airways obstruction. J Appl Physiol. 1982;53(6):1594-1602.

11. Hughson RL. Oxygen uptake kinetics: historical perspective and future directions. Appl Physiol Nutr Metab. 2009;34(5):840-850.

12. Pauwels RA, Buist AS, Calverley PM, Jenkins CR, Hurd SS. Global strategy for the diagnosis, management, and prevention of chronic obstructive pulmonary disease. NHLBI/WHO Global Initiative for Chronic Obstructive Lung Disease (GOLD) Workshop summary. Am $J$ Respir Crit Care Med. 2001;163(5):1256-1276.

13. Celli BR, Cote CG, Marin JM, et al. The body-mass index, airflow obstruction, dyspnea, and exercise capacity index in chronic obstructive pulmonary disease. N Engl J Med. 2004;350(10):1005-1012.

14. Marin JM, Cote CG, Diaz O, et al. Prognostic assessment in COPD: health related quality of life and the BODE index. Respir Med. 2011; 105(6):916-921.

15. Liu SF, Wang CC, Chin CH, Chen YC, Lin MC. High value of combined serum C-reactive protein and BODE score for mortality prediction in patients with stable COPD. Arch Bronconeumol. 2011;47(9): $427-432$.

16. Lung function testing: selection of reference values and interpretative strategies. American Thoracic Society. Am Rev Respir Dis. 1991;144(5): $1202-1218$.

17. Fabbri LM, Hurd SS. Global Strategy for the Diagnosis, Management and Prevention of COPD: 2003 update. Eur Respir J. 2003;22(1): $1-2$.

18. Knudson RJ, Lebowitz MD, Holberg CJ, Burrows B. Changes in the normal maximal expiratory flow-volume curve with growth and aging. Am Rev Respir Dis. 1983;127(6):725-734.

19. ATS Committee on Proficiency Standards for Clinical Pulmonary Function Laboratories. ATS statement: guidelines for the six-minute walk test. Am J Respir Crit Care Med. 2002;166(1):111-117.

20. Borghi-Silva A, Baldissera V, Sampaio LM, et al. L-carnitine as an ergogenic aid for patients with chronic obstructive pulmonary disease submitted to whole-body and respiratory muscle training programs. Braz J Med Biol Res. 2006;39(4):465-474.

21. Crouter SE, Antczak A, Hudak JR, DellaValle DM, Haas JD. Accuracy and reliability of the ParvoMedics TrueOne 2400 and MedGraphics VO2000 metabolic systems. Eur J Appl Physiol. 2006;98(2): 139-151.

22. Borg GA. Psychophysical bases of perceived exertion. Med Sci Sports Exerc. 1982;14(5):377-381.

23. Andrew P. Jones DCP. Oxygen Uptake Kinetics in Sport, Exercise and Medicine. New York, NY: Routledge; 2005.

24. Bearden SE, Moffatt RJ. Leg electromyography and the VO2power relationship during bicycle ergometry. Med Sci Sports Exerc. 2001;33(7):1241-1245.

25. Borrani F, Candau R, Millet GY, Perrey S, Fuchslocher J, Rouillon JD. Is the VO2 slow component dependent on progressive recruitment of fast-twitch fibers in trained runners? J Appl Physiol. 2001;90(6):2212-2220.

26. Whipp BJ, Ward SA, Lamarra N, Davis JA, Wasserman K. Parameters of ventilatory and gas exchange dynamics during exercise. $J$ Appl Physiol. 1982;52(6):1506-1513.

27. Bell C, Paterson DH, Kowalchuk JM, Padilla J, Cunningham DA. A comparison of modelling techniques used to characterise oxygen uptake kinetics during the on-transient of exercise. Exp Physiol. 2001;86(5):667-676.

28. Rossiter HB, Ward SA, Kowalchuk JM, Howe FA, Griffiths JR, Whipp BJ. Dynamic asymmetry of phosphocreatine concentration and $\mathrm{O}(2)$ uptake between the on- and off-transients of moderate- and high-intensity exercise in humans. $J$ Physiol. 2002;541(Pt 3):991-1002. 
29. Motulsky HJ, Ransnas LA. Fitting curves to data using nonlinear regression: a practical and nonmathematical review. FASEB J. 1987; 1(5):365-374.

30. Bearden SE, Moffatt RJ. VO2 and heart rate kinetics in cycling: transitions from an elevated baseline. J Appl Physiol. 2001;90(6): 2081-2087.

31. Siqueira AC, Borghi-Silva A, Bravo DM, Ferreira EM, Chiappa GR, Neder JA. Effects of hyperoxia on the dynamics of skeletal muscle oxygenation at the onset of heavy-intensity exercise in patients with COPD. Respir Physiol Neurobiol. 30, 2010;172(1-2):8-14.

32. Berton DC, Barbosa PB, Takara LS, et al. Bronchodilators accelerate the dynamics of muscle $\mathrm{O} 2$ delivery and utilisation during exercise in COPD. Thorax. 2010;65(7):588-593.

33. Hughson RL, Tschakovsky ME, Houston ME. Regulation of oxygen consumption at the onset of exercise. Exerc Sport Sci Rev. 2001;29(3): 129-133.

34. MacDonald MJ, Naylor HL, Tschakovsky ME, Hughson RL. Peripheral circulatory factors limit rate of increase in muscle $\mathrm{O}(2)$ uptake at onset of heavy exercise. J Appl Physiol. 2001;90(1):83-89.

35. Burnley M, Jones AM, Carter H, Doust JH. Effects of prior heavy exercise on phase II pulmonary oxygen uptake kinetics during heavy exercise. J Appl Physiol. 2000;89(4):1387-1396.

36. Grassi B, Poole DC, Richardson RS, Knight DR, Erickson BK, Wagner PD. Muscle $\mathrm{O} 2$ uptake kinetics in humans: implications for metabolic control. J Appl Physiol. 1996;80(3):988-998.

37. Grassi B, Gladden LB, Samaja M, Stary CM, Hogan MC. Faster adjustment of $\mathrm{O} 2$ delivery does not affect $\mathrm{V}(\mathrm{O} 2)$ on-kinetics in isolated in situ canine muscle. J Appl Physiol. 1998;85(4):1394-1403.

38. Heindl S, Lehnert M, Criee CP, Hasenfuss G, Andreas S. Marked sympathetic activation in patients with chronic respiratory failure. Am J Respir Crit Care Med. 2001;164(4):597-601.

39. Richardson RS, Sheldon J, Poole DC, Hopkins SR, Ries AL, Wagner PD. Evidence of skeletal muscle metabolic reserve during whole body exercise in patients with chronic obstructive pulmonary disease. Am J Respir Crit Care Med. 1999;159(3):881-885.

40. Borghi-Silva A, Oliveira CC, Carrascosa C, et al. Respiratory muscle unloading improves leg muscle oxygenation during exercise in patients with COPD. Thorax. 2008;63(10):910-915.

41. Gaenzer H, Neumayr G, Marschang P, Sturm W, Kirchmair R, Patsch JR. Flow-mediated vasodilation of the femoral and brachial artery induced by exercise in healthy nonsmoking and smoking men. J Am Coll Cardiol. 2001;38(5):1313-1319.
42. Chiappa GR, Queiroga F Jr, Meda E, et al. Heliox improves oxygen delivery and utilization during dynamic exercise in patients with chronic obstructive pulmonary disease. Am J Respir Crit Care Med. 2009; 179(11):1004-1010.

43. Castello-Simoes V, Polaquini Simoes R, Beltrame T, et al. Effects of aerobic exercise training on variability and heart rate kinetic during submaximal exercise after gastric bypass surgery - a randomized controlled trial. Disabil Rehabil. June 23, 2012. [Epub ahead of print.]

44. Regueiro EM, Di Lorenzo VA, Basso RP, Pessoa BV, Jamami M, Costa D. Relationship of BODE Index to functional tests in chronic obstructive pulmonary disease. Clinics (Sao Paulo). 2009;64(10): 983-988.

45. Simon KM, Carpes MF, Correa KS, dos Santos K, Karloh M, Mayer AF. Relationship between daily living activities (ADL) limitation and the BODE index in patients with chronic obstructive pulmonary disease. Rev Bras Fisioter. 2011;15(3):212-218

46. Jehn M, Schmidt-Trucksäss A, Meyer A, Schindler C, Tamm M, Stolz D. Association of daily physical activity volume and intensity with COPD severity. Respir Med. 2011;105(12):1846-1852.

47. Mantoani LC, Hernandes NA, Guimarães MM, Vitorasso RL, Probst VS, Pitta F. Does the BODE index reflect the level of physical activity in daily life in patients with COPD? Rev Bras Fisioter. 2011;15: 131-137.

48. Hughson RL. Alterations in the oxygen deficit-oxygen debt relationships with beta-adrenergic receptor blockade in man. J Physiol. 1984;349: 375-387.

49. Arena R, Humphrey R, Peberdy MA, Madigan M. Comparison of oxygen uptake on-kinetic calculations in heart failure. Med Sci Sports Exerc. 2002;34(10):1563-1569.

50. Myers J, Walsh D, Sullivan M, Froelicher V. Effect of sampling on variability and plateau in oxygen uptake. J Appl Physiol. 1990;68(1): 404-410.

51. Bauer TA, Brass EP, Nehler M, Barstow TJ, Hiatt WR. Pulmonary $\mathrm{VO} 2$ dynamics during treadmill and arm exercise in peripheral arterial disease. J Appl Physiol. 2004;97(2):627-634.

52. Brunner-La Rocca HP, Weilenmann D, Follath F, et al. Oxygen uptake kinetics during low level exercise in patients with heart failure: relation to neurohormones, peak oxygen consumption, and clinical findings. Heart. 1999;81(2):121-127.

53. Barakat S, Michele G, George P, Nicole V, Guy A. Outpatient pulmonary rehabilitation in patients with chronic obstructive pulmonary disease. Int J COPD. 2008;3(1):155-162.
International Journal of COPD

\section{Publish your work in this journal}

The International Journal of COPD is an international, peer-reviewed journal of therapeutics and pharmacology focusing on concise rapid reporting of clinical studies and reviews in COPD. Special focus is given to the pathophysiological processes underlying the disease, intervention programs, patient focused education, and self management protocols.

\section{Dovepress}

This journal is indexed on PubMed Central, MedLine and CAS. The manuscript management system is completely online and includes a very quick and fair peer-review system, which is all easy to use. Visit http://www.dovepress.com/testimonials.php to read real quotes from published authors. 